\section{The natural history of Vigabatrin associated visual field defects in patients electing to continue their medication}

$J$ Best $^{1,2}$ and JF Acheson ${ }^{1,2}$

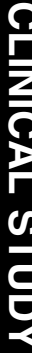

Keywords: Vigabatrin; visual field defects; drug reactions

\section{Introduction}

In 1989, Vigabatrin (Sabril, Hoechst Marion Roussel/Aventis Ltd) was introduced as a new and effective second-line antiepileptic drug for the treatment of uncontrolled complex partial seizures and infantile spasms. ${ }^{1,2}$ Since 1997 there have been numerous reports of concentric and/or binasal visual field defects associated with the use of Vigabatrin making this the most concerning safety issue with the use of the drug at present. $^{3-6}$ Previous studies have confirmed the high prevalence of visual field defects (up to $30-40 \%$ ) and the lack of evidence for significant progression or resolution of these defects on cessation of the drug. ${ }^{3,7,8}$ To date, there is little information with regard to the natural history of visual field defects in patients who continue on Vigabatrin. ${ }^{3,9}$ Our study aimed to look at the natural history of visual field defects in a group of patients with known Vigabatrin-associated field loss who opted to continue on the drug because of good seizure control and consequent improvement in quality of life.

\section{Materials and methods}

In all, 16 patients who were taking Vigabatrin alone or in combination with other antiepileptic drugs for at least 5 years (range 5-12 years) and who had been noted to have unequivocal Vigabatrin-associated visual field defects were included in the study. Patient ages ranged from 26 to 60 years, average 40 years. All patients had
${ }^{1}$ Moorfields Eye Hospital London, UK

${ }^{2}$ Departrment of Neuroophthalmology National Hospital for Neurology and Neurosurgery London, UK

Correspondence: JF Acheson Department of Neuroophthalmology The National Hospital for Neurology and Neurosurgery Queen Square, London WC1N 3BG, UK Tel: + 442078373611 ext 3382

Fax: +4420 76762041 E-mail: james.acheson@ moorfields.nhs.uk

Received: 5 June 2003 Accepted in revised form: 10 October 2003 Published online: 16 April 2004 
opted to continue on Vigabatrin despite documented field loss because of good seizure control. No patient had symptomatic field loss. Each patient was followed up at 6-monthly intervals for not less than 18 months (range 18-43 months) after discovery of the field defect. At each visit patients were asked with regard to subjective visual problems. Best-corrected distance (snellen) and near acuity were recorded. Colour vision was assessed using the 17 number plate version of the Ishihara pseudoisochromatic test. Goldmann kinetic perimetry to the V4e and I4e isopters was performed on the same regularly calibrated machine. Following already published methodology ${ }^{7}$ monocular mean radial degrees (MRDs) to the I4e isopter was calculated for the right eye at the time of discovery of the visual field defect and after a follow-up of not less than 18 months. All patients underwent a slit-lamp examination and direct and indirect dilated fundus examination at each visit.

\section{Results}

During the follow-up no patient had any subjective deterioration in visual function. All patients had an initial best-corrected distance acuity of at least 6/9 and N6 for near which did not vary significantly at subsequent visits. All, except one male who was known to be red/green colour blind, managed at least 16 out of the 17 colour plates correctly at each visit. Examination of fundi did not reveal any significant disc or macular abnormalities.

At initial detection of a visual field defect, the mean right eye visual field of the 16 patients was $36.98 \mathrm{MRD}$ (range 22.25-51.0 MRD). Three patients fell into the category of having a severe visual field defect (VF $\leq 30$ MRD). After a minimal follow-up of 18 months, the mean visual field was 38.40 MRD (range 22.5-49.75 MRD). There was no significant change in MRD between the first and final follow-up visits $(P=0.338)$ (Figure 1). Only one patient had a significant deterioration in visual field $(\geq 10 \mathrm{MRD}$ ) and was advised to discontinue Vigabatrin after 19 months follow-up (Table 1, case 3 and Figures 2 and 3). None of the three patients with severe constriction of visual field showed any further deterioration over at least 22 months follow-up. One of these patients with an initial mean visual field of 22.25 MRD had a final mean visual field of 22.5 MRD after 41 months follow-up (Table 1).

\section{Discussion}

Although the exact pathophysiological mechanisms of vigabatrin-associated visual field defects remain unclear the site of toxicity is proposed to be located at the inner retina, where vigabatrin causes irreversible inhibition of

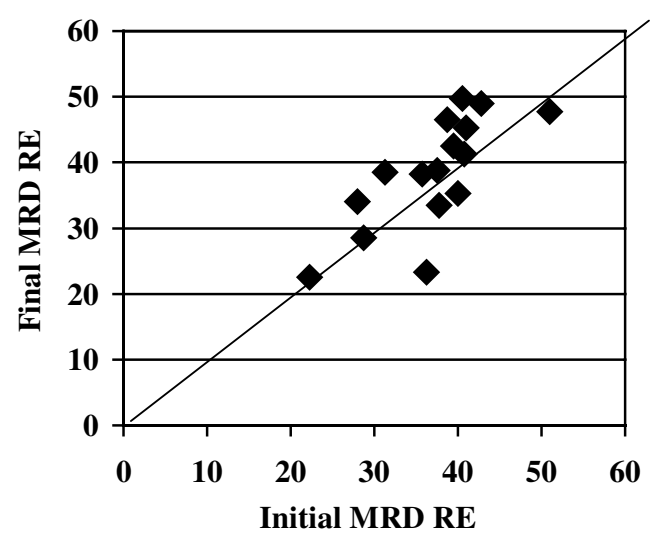

Figure 1 Visual fields in MRD at first recording of a defect plotted against visual field in MRD after a minimum follow-up of 18 months.

GABA aminotransferase with consequent elevation of GABA, a major inhibitory transmitter in the brain and retina. ${ }^{10,11}$ Male preponderance and a lack of relationship between visual loss and cumulative dosage has given rise to the suggestion that an idiosyncratic drug reaction within the neurosensory retina may underlie the pathogenesis of the visual field loss with interindividual susceptibility. ${ }^{7}$ If this was the case, the acquired visual field defect would be expected to remain reasonably stable whether treatment was ceased or not. A recent study by Newman et $\mathrm{al}^{7}$ showed no evidence of progression or resolution of visual field defects in 21 patients on discontinuing the drug.

Although there have been a few reported cases of improvement in visual field after withdrawal of vigabatrin, ${ }^{12-14}$ other larger studies suggest that field loss is irreversible. ${ }^{3,15-17}$ Several studies have also found no correlation between either treatment duration or cumulative dosage and visual field loss., ${ }^{3,8}$ The question as to whether field loss is not only irreversible but progressive with continued use of vigabatrin is less clear. Evidence from this study suggests that visual field defects do not progress significantly or at least appear to plateau with continued use of the drug and do not appear to be dose dependent. Recently, Nousiainen et $a l^{3}$ found that after discontinuation of the drug, no significant recovery was observed in visual fields during follow-up, but conversely, no progression was found with continued therapy.

Paul et $a l^{9}$ showed similar findings in their study. This evidence lends further support to the idea that an idiosyncratic drug reaction may underlie the pathogenesis in some patients. Genetically determined variations in local tissue drug or metabolite deactivation or clearance most probably in the retina are likely to be relevant. $^{7}$ This may have important implications for the quality of life in some patients in whom seizure control 
Table 1 (MRDs) field at first assessment and final follow-up

\begin{tabular}{|c|c|c|c|c|c|}
\hline $\begin{array}{l}\text { Patient } \\
\text { number }\end{array}$ & $\begin{array}{c}\text { Duration of } \\
\text { Vigabatrin Tx.(yrs) }\end{array}$ & $\begin{array}{c}\text { Daily } \\
\text { dose }(g)\end{array}$ & $\begin{array}{c}\text { Follow-up after } \\
\text { VF defect detected (months) }\end{array}$ & Initial MRD RE & Final $M R D R E$ \\
\hline 1 & 5 & 3 & 18 & 39.5 & 42.5 \\
\hline 2 & 8 & 3 & 24 & 37.5 & 38.75 \\
\hline 3 & 8 & 1.5 & 19 & 36.25 & 23.25 \\
\hline 4 & 8 & 1.5 & 27 & 41 & 45.25 \\
\hline 5 & 7 & 2.5 & 35 & 40.75 & 41.25 \\
\hline 6 & 6 & 2 & 35 & 51 & 47.75 \\
\hline 7 & 10 & 4 & 23 & 35.75 & 38.25 \\
\hline 8 & 12 & 4 & 35 & 37.75 & 33.5 \\
\hline 9 & 7 & 1 & 21 & 40.5 & 49.75 \\
\hline 10 & 8 & 1.5 & 43 & 40.0 & 35.25 \\
\hline 11 & 10 & 3 & 41 & 22.25 & 22.5 \\
\hline 12 & 5 & 1.5 & 18 & 42.75 & 49 \\
\hline 13 & 10 & 2 & 18 & 38.75 & 46.5 \\
\hline 14 & 6 & 3 & 19 & 31.25 & 38.5 \\
\hline 15 & 5 & 3 & 22 & 28 & 34 \\
\hline 16 & 8 & 1.5 & 31 & 28.75 & 28.5 \\
\hline \multicolumn{4}{|c|}{ Mean of MRD for the 16 eyes } & 36.98 & 38.40 \\
\hline
\end{tabular}

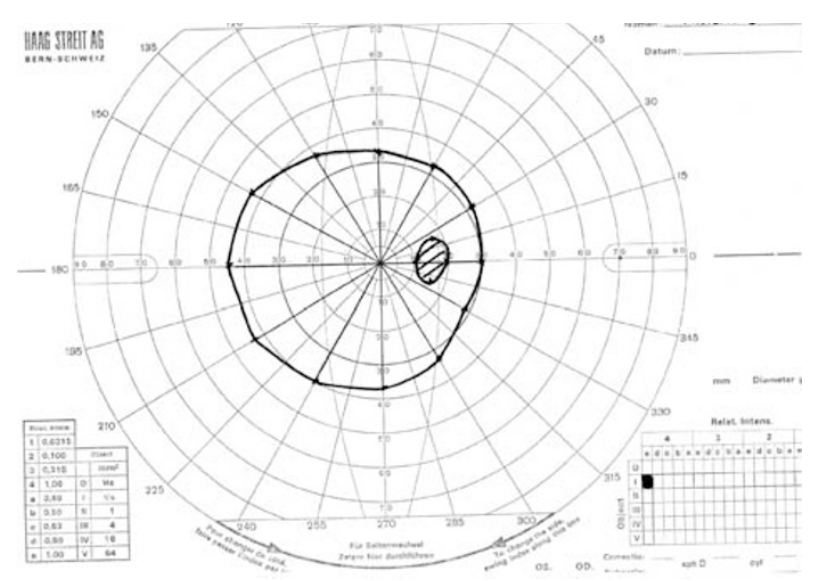

Figure 2 Initial visual field of right eye of patient 3.

with other antiepileptic medication has been difficult to achieve. If the risk from uncontrolled seizures outweighed the risk of progressive field loss patients then neurologists might be more confident at opting to

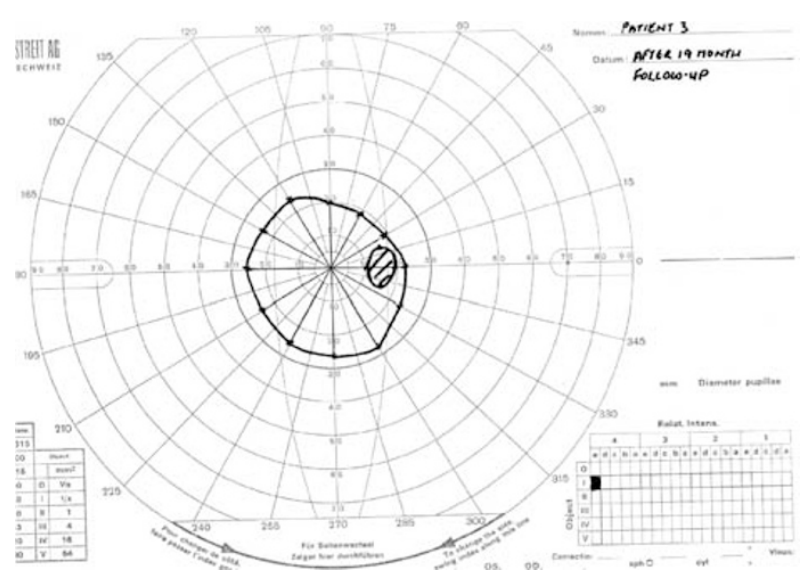

Figure 3 Visual field of right eye of patient 3 after 19 months follow-up.

continue vigabatrin. In the meantime patients should continue to be fully informed of the prevalence of visual field defects in vigabatrin users. 


\section{References}

1 Ben-Menachem E. Vigabatrin. Epilepsia 1995; 36: S95-S104.

2 Marson AG, Kadir ZA, Hutton JL, Chadwick DW. The new antiepileptic drugs: a systemic review of their efficacy and tolerability. Epilepsia 1997; 38: 859-880.

3 Nousianen, Mantyjarvi M, Kalviainen R. No reversion in vigabatrin-associated field defects. Neurology 2001; 57: 1916-1917.

4 Wild JM, Martinez C, Reinshagen G, Harding G. Characteristics of a unique visual field defect attributed to vigabatrin. Epilepsia 1999; 40(12): 1784-1794.

5 Kalviainen R, Nousiainen I, Mantyjarvi M, Nikoskelainer E, Pastaner J, Pastaner $\mathrm{K}$ et al. Vigabatrin, a gabaergic antiepileptic drug, causes concentric visual field defects. Neurology 1999; 53: 922-926.

6 Lawden MC, Eke T, Degg C, Harding GFA, Wild JM. Visual field defects associated with vigabatrin therapy. J Neurol Neurosurg Psychiatry 1999; 67: 716-722.

7 Newman WD, Tocher K, Acheson J. Vigabatrin associated visual field loss: a clinical audit to study prevalence, drug history and effects of drug withdrawal. Eye 2002; 16: 567-571.

8 Johnson MA, Krauss GL, Miller NR, Medura M, Paul SR. Visual function loss from vigabatrin: effect of stopping the drug. Neurology 2000; 55: 40-45.

9 Krakow K, Polizzi G, Riordan- Eva P, Holder G, MacLeod WN, Fish DR. Recovery of visual field constriction following discontinuation of vigabatrin. Seizure 2000; 9: 287-290.
10 Giordano L, Valseriati D, Vignoli A, Morescalchi F, Gandolfo E. Another case of reversibility of visual field defects induced by vigabatrin monotherapy: is young age a favourable factor? Neurol Sci 2000; 21: 185-186.

11 Kraemer G, Ried S, Landau K, Harding GFA. Vigabatrin. Reversibility of severe concentric visual field defects after early detection and drug withdrawal:a case report. Epilepsia 2000; 41(Suppl): 144.

12 Van Der Torren Kors, Graniewski-Wijnands HS, Polak BCP. Visual field and electrophysiological abnormalities due to vigabatrin. Documenta. Ophthalmologica 2002; 104: 181-188.

13 Coupland SG, Zackro DH, Leonard BC, Ross TM Vigabatrin effect on inner retinal function. Ophthalmology 2001; 108: 1493-1496.

14 Eke T, Talbot JF, Lawden MC. Severe persistent visual field constriction associated with vigabatrin. BMJ 1997; 314: 180-181.

15 Wilson EA, Brodie MJ, Wong IC, Mawer GE, Sander JWAS, Blackwell $\mathrm{N}$ et al. Severe persistent visual field constriction associated with vigabatrin (multiple letters). BMJ 1997; 314: 1693-1695.

16 Harding HFA, Mackenzie R, Klistorner A. Severe persistent visual field constriction associated with vigabatrin. $B M J$ 1998; 316: 232-233.

17 Paul SR, Krauss GL, Miller NR, Medura M, Miller TA, Johnson MA et al. Visual function is stable in patients who continue long-term vigabatrin therapy: implications for clinical decision making. Epilepsia 2001; 42: 525-530. 